\title{
Programas de formação inicial de professores: um estudo de caso sobre o Pibid no Distrito Federal
}

\author{
Programs of initial teacher formation: a case study about the Pibid \\ in Distrito Federal
}

\author{
Daniel de Freitas Nunes* \\ Universidade de Brasília \\ Lucas Lopes de Santana** \\ Universidade de Brasília \\ Kátia Augusta Curado Pinheiro Cordeiro da Silva*** \\ Universidade de Brasília
}

Resumo Este artigo apresenta resultados de um estudo exploratório sobre a base de dados do Programa de Bolsas de Iniciação à Docência (Pibid), com vistas a verificar a aderência - e a natureza desta aderência - a este programa em cursos de licenciaturas das Instituições de Ensino Superior (IES) no Distrito Federal (DF).Objetivamente, pretende-se discutir a aderência das IES do DF ao Pibid a partir do cruzamento de informações da base de dados do programa e da educação superior. Metodologicamente, o estudo caracteriza-se como um estudo de caso. Discute-se, a partir dos resultados apresentados, que as instituições participantes do programa no DF possuem perfis heterogêneos tanto no que diz respeito aos cursos quanto ao aproveitamento da cota de bolsas e aderência ao programa.

PALAVRAS-CHAVE: Educação, mediação pedagógica, economia solidária, trabalho associado.

\begin{abstract}
This paper presents results of an exploratory study on the database of the Scholarship Program of initiation to Teaching (Pibid - in portuguese), with the intention of verify the adherence - and the nature of this adherence - to this program on teacher formation undergraduate courses of Higher Education Institutions (HEI) in the Distrito Federal (DF). Objectively, we intend to discuss adherence of the HEI of the DF to the Pibid with crossing information of the database of the program and the higher education census. Methodologically, the study is characterized as a case study. It discusses, from the results presented, that the institutions participating in the program in the DF have heterogeneous profiles both with regard to courses on the use of the quota of scholarships and adherence to the program.
\end{abstract}

KEYWORDS: Pibid, initial formation, graduation 


\section{Introdução}

Como postula Nóvoa (2009), tem-se, no início do século XXI, um retorno do professor ao centro das preocupações educativas. No Brasil, em tempos de reformas e reformulações de políticas educacionais, figuradas no acalorado debate em torno novo Plano Nacional de Educação (PNE), o cenário não é diferente. Como postula Freitas (2002), em tempos de reformas educacionais, a educação e a formação de professores assumem papéis de importância estratégica.

Em que pese o calor das discussões que se façam, ao se partir de uma perspectiva pragmática, a melhoria do sistema educacional nacional antes de ser uma questão social é também, uma necessidade econômica. Não obstante, como postula Schleicher (2007), a capacidade dos países - tanto os desenvolvidos como os em desenvolvimento - de competir no mercado global do conhecimento passa, necessariamente, pela formação de mão de obra de alto nível, e consequentemente, por melhores índices escolares.

Como observa Gatti \& Nunes (2009), o desempenho questionável do país em avaliações nacionais e internacionais tem fomentado importantes debates sobre os fatores que implicam na melhoria da qualidade das escolas no país, sendo que a formação de professores é apontada como um fator de considerável peso.

Diante desse problemático contexto, o que se observa, no âmbito das políticas públicas para formação de professores, é o surgimento de ambiciosos programas criados sob a alegação da melhoria da qualidade da formação de professores no Brasil.

Um marco importante para análise de tais políticas é, sem dúvida, a realização do "Estudo Exploratório do Professor Brasileiro", pelo Instituto Nacional de Pesquisas Educacionais Anísio Teixeira - INEP (INEP, 2009), que no ano de 2009 apresentou um detalhado raio "X" quantitativo da situação do professor das escolas públicas brasileiras, no qual traduziu em números, problemas históricos que sempre implicaram na qualidade do professorado nacional, como falta de qualificação mínima (curso superior), e discrepâncias regionais quanto ao perfil qualitativo do professor Brasileiro.

Concomitantemente à realização deste estudo, o Ministério da Educação (MEC) desenhou dois ambiciosos programas de formação inicial de professores: $\mathrm{O}$ programa Institucional de Bolsas de Iniciação à Docência (Pibid) e o Plano Nacional de Formação de Professores da Educação Básica (Parfor). Ambos visavam resolver problemas históricos do sistema educacional Brasileiro: a ineficiente e descontextualizada formação de professores nas universidades brasileiras, colocada há tempos sob suspeitas por inúmeras pesquisas e a atestada falta de professores com formação mínima exigida (nível superior) pela Lei de Diretrizes e Bases da Educação Nacional (LDBEN) de 1996 (BRASIL, 1996).

O programa de interesse desta pesquisa- Pibid - foi formalizado por meio de seleção pública realizada no ano de 2007 (MEC; CAPES; FNDE, 2007). De acordo com seu escopo, este programa é uma política de indução à ampliação da forma- 
ção prática inicial dos estudantes de licenciatura, por meio da inserção assistida no cotidiano de escolas de educação básica da rede pública. Embora seja uma política de formação inicial docente, o Pibid não tem o intuito de substituir o estágio curricular obrigatório: neste programa, os estudantes devem elaborar e executar atividades de cunho experimental e tendencialmente inovador, sendo vedada a regência de turma. A implementação do programa foi norteada pelos seguintes objetivos:

a) incentivar a formação de professores para a educação básica, especialmente para o ensino médio;

b) valorizar o magistério, incentivando os estudantes que optam pela carreira docente;

c) promover a melhoria da qualidade da educação básica;

d) promover a articulação integrada da educação superior do sistema federal com a educação básica do sistema público, em proveito de uma sólida formação docente inicial;

e) elevar a qualidade das ações acadêmicas voltadas à formação inicial de professores nos cursos de licenciaturas das instituições federais de educação superior;

f) estimular a integração da educação superior com a educação básica no ensino fundamental e médio, de modo a estabelecer projetos de cooperação que elevem a qualidade do ensino nas escolas da rede pública;

g) fomentar experiências metodológicas e práticas docentes de caráter inovador, que utilizem recursos de tecnologia da informação e da comunicação, e que se orientem para a superação de problemas identificados no processo ensino-aprendizagem;

h) valorização do espaço da escola pública como campo de experiência para a construção do conhecimento na formação de professores para a educação básica;

i) proporcionar aos futuros professores participação em ações, experiências metodológicas e práticas docentes inovadoras, articuladas com a realidade local da escola (MEC/CAPES/FNDE, 2007, p. 1-2).

Resumidamente, o Pibid consiste no pagamento de bolsas em quatro níveis de participação: professores de escolas, alunos de licenciatura, professores de licenciatura e coordenador de projeto (outro professor universitário). Aqui nos deteremos a analisar apenas o quantitativo de alunos de licenciatura participantes do programa no Distrito Federal, DF.

O gerenciamento do programa está a cargo da Coordenação de Aperfeiçoamento de Pessoal de Nível Superior - Capes. Em 2007, a Capes foi incumbida de desenhar e implementar políticas de formação de professores para atuação na educação básica - dentre as quais está o Pibid - todas unificadas em 2009 na Política Nacional de Profissionais do Magistério da Educação Básica (BRASIL, 2009). 
O programa passou recentemente, em 2013, por uma ampla reformulação e uma forte expansão quantitativa pode ser percebida a partir da mais recente seleção do programa, convocada pelo Edital Capes no 61/2013 (CAPES, 2013): em abril de 2014, 81.177 mil bolsas foram pagas por meio do Sistema de Acompanhamento de Concessões da Capes - SAC, das quais 65.928 mil são destinadas a licenciandos (CAPES, 2014). Em 2009, segundo ano de execução do programa, o número de bolsistas oriundos da primeira seleção - ocorrida em 2007 - era de 3.088 no total, conforme o Relatório de Gestão da Diretoria de Educação Básica Presencial - DEB (CAPES, 2012). Isto corresponde a um crescimento de aproximadamente 26 vezes no total geral de bolsistas em cinco anos.

\section{Notas Metodológicas}

O presente estudo caracteriza-se como um estudo de caso instrumental. Como postula Creswell (2012), o estudo de caso constitui-se na análise em profundidade de um caso delimitado amparado em uma extensa coleta de dados. No que diz respeito a qualificação do tipo de estudo de caso, ainda segundo o autor, o tipo instrumental caracteriza-se pelo fato de ser um caso estudado que pode fornecer insights para o tema em questão.

Considerando que, no ano de 2013, 272 IES públicas e privadas do país aprovaram projetos Pibid (CAPES, 2014) de um extremo geográfico ao outro, contemplando as 27 unidades federativas, torna-se consideravelmente exaustivo e demorado avaliar qualquer aspecto do programa em sua amplitude sem contar com uma grande equipe de pesquisadores e recursos para isso. Nesse sentido, diante das limitações materiais inerentes à presente pesquisa, isolamos um caso dentre as 27 unidades federativas (Distrito Federal - DF), com vistas a precisar e fornecer informações sobre a aderência dos cursos de licenciatura das IES do DF ao programa em questão. Entende-se que, mesmo com a possível interferência de questões contextuais regionais, o presente estudo pode prover resultados que venham a contextualizar e subsidiar pesquisas futuras concernentes ao tema em tela.

Deste modo, os dados apresentados neste artigo consistem de informações extraídas dos microdados do censo da educação superior de $2012^{1}$ e do sistema de pagamento de bolsas e da base de dados do Pibid/Capes. Os dados de referência, no que diz respeito ao quantitativo de bolsistas de cada curso e instituição, foram levantados a partir do relatório de bolsistas ativos do Pibid referente ao mês 05/2014. Os microdados foram extraídos a partir do programa SPSS (StatisticalPackage for the Social Sciences) versão 17.0 e as tabelas e figuras foram formatadas no Microsoft EXCEL 2013.

A população pesquisada constitui de todos os estudantes dos cursos de licenciaturas presenciais, com situação de matrícula ${ }^{2}$, das instituições participantes do programa no DF: a Universidade de Brasília (UnB), Universidade Católica de Brasília (UCB), Instituto Federal de Educação Ciência e Tecnologia do DF (IFB) e Faculdade Jesus Maria José (FAJESU). 
Nesse sentido, foram quantificados os dados referentes ao quantitativo de matrículas, filtrados pelo código das Instituições de Ensino Superior participantes que constam na planilha de projetos aprovados da Capes, pelo grau acadêmico (licenciatura), modalidade de ensino (presencial) e turno dos cursos em cada instituição.

No que diz respeito à quantificação dos bolsistas de cada instituição, vale ressaltar que utiliza-se aqui o conceito de "bolsista ativo". Segundo a Capes, bolsista ativo é aquele já foi pago ao menos uma vez com sucesso; portanto, disto tiramos algumas conclusões: 1) o sujeito fora aprovado na seleção do Pibid e iniciara suas atividades; portanto, foi inscrito para pagamento, e aparece para a Capes como bolsista e pode ser quantificado como tal; 2) o conceito de bolsista ativo é altamente confiável por ser atualizado mensalmente.

Quantitativamente, apresentam-se resultados comparando a quantidade de bolsistas em relação ao total de matriculados por curso e instituição em termos percentuais, bem como do aproveitamento da cota de bolsas por curso e por instituição. A intenção foi verificar a aderência por curso e instituição - expressada pela quantidade de bolsistas por curso e instituição - bem como o aproveitamento, em termos percentuais, da cota de bolsas também por curso e instituição. Dessa maneira, a discussão dos resultados organiza-se em três seções. Na primeira seção, que divide-se em quatro subseções, apresentam-se os resultados por cada instituição participante do programa no DF. Na penúltima seção, fazemos algumas comparações gerais entre o perfil de aderência ao programa da IES do DF, sendo que na última seção, apresentamos as considerações finais com sugestões para estudos futuros.

\section{Resultados}

Para otimizar a discussão dos resultados, estes são descritos por instituição, o que no nosso entender facilitará a visualização dos dados aqui apresentados. Para tal, as instituições são apresentadas de maneira decrescente no que diz respeito à quantidade de bolsistas. Deste modo, apresentamos respectivamente os resultados da UnB, UCB, FAJESU e IFB discutindo aspectos convergentes e/ou peculiares da aderência ao programa em cada instituição.

\section{Perfil do Pibid UnB}

De acordo com os microdados do censo, a UnB possuía, em 2012, 5.744 alunos matriculados nos cursos presenciais de licenciatura da instituição, divididos quase que equitativamente entre cursos de turno integral, 50\%, e cursos noturnos, 49,7\% (Tabela 1). 
Daniel de Freitas Nunes - Lucas Lopes de Santana - Kátia Augusta

Curado Pinheiro Cordeiro da Silva

\begin{tabular}{|c|c|c|c|c|c|}
\hline \multirow[b]{2}{*}{ Nome do curso } & \multicolumn{3}{|c|}{ Turno e \% por turno } & \multirow[b]{2}{*}{$\%$} & \multirow[b]{2}{*}{ Total } \\
\hline & Integral & $\%$ & Noturno & & \\
\hline Artes cênicas & 84 & $72 \%$ & 33 & $28 \%$ & 117 \\
\hline Artes plásticas & 113 & $59 \%$ & 80 & $41 \%$ & 193 \\
\hline Ciências biológicas & 49 & $15 \%$ & 280 & $85 \%$ & 329 \\
\hline Ciências naturais-planaltina & 233 & $58 \%$ & 172 & $42 \%$ & 405 \\
\hline Ciências sociais & 66 & $100 \%$ & 0 & $0 \%$ & 66 \\
\hline Computação & 0 & $0 \%$ & 231 & $100 \%$ & 231 \\
\hline Educação artística & 76 & $97 \%$ & 2 & $3 \%$ & 78 \\
\hline Educação do campo & 230 & $100 \%$ & 0 & $0 \%$ & 230 \\
\hline Educação física & 432 & $100 \%$ & 0 & $0 \%$ & 432 \\
\hline Enfermagem & 39 & $100 \%$ & 0 & $0 \%$ & 39 \\
\hline Filosofia & 170 & $62 \%$ & 104 & $38 \%$ & 274 \\
\hline Física & 16 & $12 \%$ & 122 & $88 \%$ & 138 \\
\hline Geografia & 93 & $100 \%$ & 0 & $0 \%$ & 93 \\
\hline História & 92 & $33 \%$ & 183 & $67 \%$ & 275 \\
\hline Letras & 74 & $100 \%$ & 0 & $0 \%$ & 74 \\
\hline Letras - espanhol & 0 & $0 \%$ & 244 & $100 \%$ & 244 \\
\hline Letras - francês & 70 & $100 \%$ & 0 & $0 \%$ & 70 \\
\hline Letras - inglês & 85 & $100 \%$ & 0 & $0 \%$ & 85 \\
\hline Letras - japonês & 0 & $0 \%$ & 134 & $100 \%$ & 134 \\
\hline Letras - língua portuguesa & 186 & $100 \%$ & 0 & $0 \%$ & 186 \\
\hline Letras - português & 46 & $12 \%$ & 346 & $88 \%$ & 392 \\
\hline Letras tradução espanhol & 0 & $0 \%$ & 132 & $100 \%$ & 132 \\
\hline Matemática & 101 & $44 \%$ & 129 & $56 \%$ & 230 \\
\hline Música & 12 & $10 \%$ & 113 & $90 \%$ & 125 \\
\hline Pedagogia & 597 & $64 \%$ & 335 & $36 \%$ & 932 \\
\hline Psicologia & 16 & $100 \%$ & 0 & $0 \%$ & 16 \\
\hline Química & 11 & $5 \%$ & 213 & $95 \%$ & 224 \\
\hline Total & 2891 & $50 \%$ & 2853 & $49,7 \%$ & 5744 \\
\hline
\end{tabular}

Tabela 1: Quantidade de alunos na situação de matriculados nos cursos de licenciatura da UnB por turno. Fonte: Microdados do censo da Educação Superior 2012.

Com um perfil diversificado de cursos, as licenciaturas da UnB apresentam um perfil heterogêneo que contemplam diferentes áreas de concentração. De todo modo, levando-se em consideração que o interesse do presente estudo são os alunos na situação de "cursando", na tabela 2, apresentam-se os dados relativos aos alunos que se encontram nessa condição. 


\begin{tabular}{|c|c|c|c|c|c|c|c|}
\hline \multirow[b]{2}{*}{ Nome do curso } & \multicolumn{2}{|c|}{ Situação do aluno } & \multirow[b]{2}{*}{$\%$} & \multirow[b]{2}{*}{$\begin{array}{c}\text { cota } \\
\text { solicitada }\end{array}$} & \multirow[b]{2}{*}{$\begin{array}{c}\text { qtde de } \\
\text { bolsistas }\end{array}$} & \multirow[b]{2}{*}{$\begin{array}{c}\% \text { de } \\
\text { aproveitamento } \\
\text { da cota }\end{array}$} & \multirow[b]{2}{*}{$\begin{array}{c}\% \\
\text { por } \\
\text { curso }\end{array}$} \\
\hline & matriculado & cursando & & & & & \\
\hline Artes cênicas & 117 & 105 & $90 \%$ & 20 & 19 & $95 \%$ & $18 \%$ \\
\hline Artes plásticas & 193 & 161 & $83 \%$ & - & - & - & - \\
\hline $\begin{array}{l}\text { Ciências } \\
\text { biológicas }\end{array}$ & 329 & 264 & $80 \%$ & 21 & 19 & $90 \%$ & $7 \%$ \\
\hline $\begin{array}{l}\text { Ciências naturais } \\
\text {-planaltina }\end{array}$ & 405 & 365 & $90 \%$ & 24 & 24 & $100 \%$ & $7 \%$ \\
\hline Ciências sociais & 66 & 39 & $59 \%$ & 10 & 9 & $90 \%$ & $23 \%$ \\
\hline Computação & 231 & 208 & $90 \%$ & 5 & 5 & $100 \%$ & $2 \%$ \\
\hline Educação artística & 78 & 58 & $74 \%$ & - & - & - & - \\
\hline $\begin{array}{l}\text { Educação do } \\
\text { campo }\end{array}$ & 230 & 208 & $90 \%$ & - & - & - & - \\
\hline Educação física & 432 & 366 & $85 \%$ & 40 & 17 & $43 \%$ & $5 \%$ \\
\hline Enfermagem & 39 & 31 & $79 \%$ & - & - & - & - \\
\hline Filosofia & 274 & 248 & $91 \%$ & 30 & 23 & $77 \%$ & $9 \%$ \\
\hline Física & 138 & 121 & $88 \%$ & 21 & 9 & $43 \%$ & $7 \%$ \\
\hline Geografia & 93 & 64 & $69 \%$ & - & - & - & - \\
\hline História & 275 & 257 & $93 \%$ & - & - & - & - \\
\hline Letras & 74 & 49 & $66 \%$ & - & - & - & - \\
\hline Letras - espanhol & 244 & 216 & $89 \%$ & - & - & - & - \\
\hline Letras - francês & 70 & 58 & $83 \%$ & - & - & - & - \\
\hline Letras - inglês & 85 & 61 & $72 \%$ & 10 & 9 & $90 \%$ & $15 \%$ \\
\hline Letras - japonês & 134 & 128 & $96 \%$ & - & - & - & - \\
\hline $\begin{array}{l}\text { Letras - língua } \\
\text { portuguesa }\end{array}$ & 186 & 158 & $85 \%$ & - & - & - & - \\
\hline $\begin{array}{l}\text { Letras - } \\
\text { português }\end{array}$ & 392 & 336 & $86 \%$ & 21 & 19 & $90 \%$ & $6 \%$ \\
\hline $\begin{array}{l}\text { Letras tradução } \\
\text { espanhol }\end{array}$ & 132 & 132 & $100 \%$ & - & - & - & - \\
\hline Matemática & 230 & 203 & $88 \%$ & 15 & 12 & $80 \%$ & $6 \%$ \\
\hline Música & 125 & 121 & $97 \%$ & 15 & 12 & $80 \%$ & $10 \%$ \\
\hline Pedagogia & 932 & 784 & $84 \%$ & 30 & 28 & $93 \%$ & $4 \%$ \\
\hline Psicologia & 16 & 7 & $44 \%$ & - & - & - & - \\
\hline Química & 224 & 187 & $83 \%$ & 30 & 22 & $73 \%$ & $12 \%$ \\
\hline Total & 5744 & 4935 & $86 \%$ & 292 & 227 & $78 \%$ & $5 \%$ \\
\hline
\end{tabular}

Tabela 2: Quantidade de matriculados, quantidade de alunos na situação de "cursando", percentual de "cursando" em relação ao total de matriculados, cota de bolsas solicitadas, quantidade de bolsistas de cada curso, percentual de aproveitamento da cota em cada curso e percentual de bolsistas de cada curso em relação ao total de "cursando" UnB. Fonte: Microdados do censo da Educação Superior 2012/CAPES. Obs: os cursos de Artes Cênicas e Computação constam na planilha da Capes como "Teatro" e "Informática, respectivamente. 
O que se pode observar quanto à UnB, maior instituição pública de Ensino Superior do DF, é que, embora $52 \%$ dos $27^{3}$ cursos de licenciatura presenciais da instituição façam parte do Pibid, a inserção da instituição no programa ainda é tímida: comparativamente, apenas 5\% dos alunos na situação de "cursando" da instituição fazem parte do programa. Outro fato que deve ser mencionado sobre a UnB é o baixo aproveitamento das cotas de bolsas: para se ter uma ideia, da cota de 292 bolsas demanda pela instituição, foi aproveitado apenas 78\% (tabela 2).

O que se pode inferir, no caso da UnB, é que à aderência dos cursos de licenciatura da instituição ao Pibid não se dá de forma homogênea, estando os cursos da área de ciências exatas de Química, Física e Matemática entre os que menos aproveitaram suas cotas de bolsas.

Tais números indicam, possivelmente, problemas de gerenciamento institucional do programa. Há ainda de se ressaltar que os dados sobre matrícula dos quais lança-se mão aqui são relativos a 2012, o que indica que se fosse já possível comparar com os dados de 2013, esse percentual de participação certamente seria menor.

\section{Perfil do Pibid UCB}

Segundo os microdados do censo, a UCB possuía 3.012 alunos matriculados nos nove cursos presenciais de licenciatura da instituição, divididos nos turnos matutino, vespertino e noturno, sendo a quantidade de matriculados nesse turno predominante: $61 \%$ contra $38 \%$ do turno matutino, evidenciando um perfil diferenciando se comparado à UnB: enquanto $50 \%$ dos cursos das matrículas de alunos de licenciatura dessa instituição encontram-se em cursos de tempo integral, a UCB não registra nenhum curso integral (tabela 3).

\begin{tabular}{|c|c|c|c|c|c|c|c|}
\hline \multirow[b]{2}{*}{ Nome do curso } & \multicolumn{6}{|c|}{ Turno e $\%$ por turno } & \multirow[b]{2}{*}{ Total } \\
\hline & Matutino & $\%$ & Noturno & $\%$ & Vespertino & $\%$ & \\
\hline Ciências Biológicas & 269 & $66 \%$ & 134 & $33 \%$ & 3 & $1 \%$ & 406 \\
\hline Educação Física & 610 & $47 \%$ & 682 & $52 \%$ & 12 & $1 \%$ & 1304 \\
\hline Filosofia & 0 & $0 \%$ & 54 & $100 \%$ & 0 & $0 \%$ & 54 \\
\hline Física & 0 & $0 \%$ & 104 & $100 \%$ & 0 & $0 \%$ & 104 \\
\hline Letras - Inglês & 174 & $67 \%$ & 84 & $33 \%$ & 0 & $0 \%$ & 258 \\
\hline Letras - Português & 103 & $43 \%$ & 135 & $57 \%$ & 0 & $0 \%$ & 238 \\
\hline Matemática & 0 & $0 \%$ & 125 & $100 \%$ & 0 & $0 \%$ & 125 \\
\hline Pedagogia & 0 & $0 \%$ & 385 & $100 \%$ & 0 & $0 \%$ & 385 \\
\hline Química & 0 & $0 \%$ & 137 & $99 \%$ & 1 & $1 \%$ & 138 \\
\hline Total & 1156 & $38 \%$ & 1840 & $61 \%$ & 16 & $1 \%$ & 3012 \\
\hline
\end{tabular}

Tabela 3: Quantidade de matrículas nos cursos de licenciatura da UCB por turno. Fonte: Microdados do censo da Educação Superior 2012.

De todo modo, quando se verifica a aderência ao programa, observa-se uma maior inserção desta instituição no Pibid. Nesse sentido, o primeiro dado que merece 
registro é a abrangente aderência da instituição ao programa: dos nove cursos presenciais de licenciatura levantados pelo censo de 2012, todos fazem parte do programa, o que perfaz uma adesão de 100\% (Tabela 4), bem mais significativa do que da UnB em termos percentuais e a mais significativa das instituições do DF.

\begin{tabular}{|c|c|c|c|c|c|c|c|}
\hline \multirow[b]{2}{*}{ Nome do Curso } & \multicolumn{2}{|c|}{ Situação do aluno } & \multirow[b]{2}{*}{$\%$} & \multirow[b]{2}{*}{$\begin{array}{c}\text { Cota } \\
\text { Solicitada }\end{array}$} & \multirow[b]{2}{*}{$\begin{array}{l}\text { Qtde de } \\
\text { Bolsistas }\end{array}$} & \multirow[b]{2}{*}{$\begin{array}{c}\% \text { de } \\
\begin{array}{c}\text { Aproveitamento } \\
\text { da Cota }\end{array}\end{array}$} & \multirow[b]{2}{*}{$\begin{array}{c}\% \text { Por } \\
\text { Cur- } \\
\text { so }\end{array}$} \\
\hline & $\begin{array}{l}\text { Matrícu- } \\
\text { las }\end{array}$ & $\begin{array}{c}\text { Cursan- } \\
\text { do }\end{array}$ & & & & & \\
\hline $\begin{array}{l}\text { Ciências } \\
\text { Biológicas }\end{array}$ & 406 & 336 & $83 \%$ & 10 & 9 & $90 \%$ & $3 \%$ \\
\hline Educação Física & 1304 & 1075 & $82 \%$ & 20 & 20 & $100 \%$ & $2 \%$ \\
\hline Filosofia & 54 & 40 & $74 \%$ & 7 & 7 & $100 \%$ & $18 \%$ \\
\hline Física & 104 & 79 & $76 \%$ & 6 & 6 & $100 \%$ & $8 \%$ \\
\hline Letras - Inglês & 258 & 219 & $85 \%$ & 20 & 12 & $60 \%$ & $5 \%$ \\
\hline $\begin{array}{l}\text { Letras - } \\
\text { Português }\end{array}$ & 238 & 195 & $82 \%$ & 10 & 10 & $100 \%$ & $5 \%$ \\
\hline Matemática & 125 & 91 & $73 \%$ & 6 & 6 & $100 \%$ & $7 \%$ \\
\hline Pedagogia & 385 & 269 & $70 \%$ & 20 & 17 & $85 \%$ & $6 \%$ \\
\hline Química & 138 & 112 & $81 \%$ & 10 & 9 & $90 \%$ & $8 \%$ \\
\hline Total & 3012 & 2416 & $80 \%$ & 109 & 96 & $88 \%$ & $4 \%$ \\
\hline
\end{tabular}

Tabela 4: Quantidade de matriculados, quantidade de alunos na situação de "cursando", percentual de "cursando" em relação ao total de matriculados, cota de bolsas solicitadas, quantidade de bolsistas de cada curso, percentual de aproveitamento da cota em cada curso e percentual de bolsistas de cada curso em relação total em relação ao total de "cursando" UCB. Fonte: Microdados do censo da Educação Superior 2012/CAPES.

Merece registo também o percentual de aproveitamento da cota de bolsas, que é superior ao da UnB, perfazendo $88 \%$ : $10 \%$ a mais e à uma média por curso também superior, que alcança o percentual de $92 \%$.

O que se pode inferir, no caso da UCB, é que a instituição aparentemente gere mais eficientemente o programa, tanto na aderência dos cursos quanto no aproveitamento da cota de bolsas. Certamente, deve se registrar aqui que por se tratar de uma instituição privada, essa "eficiência" e aderência pode ser explicada a partir do momento em que a bolsa pode significar um fator de atratividade e permanência dos alunos nos cursos, já que são cursos pagos. De todo modo, trata-se de uma hipótese secundária, que necessariamente carece de ser testada a partir de um estudo mais aprofundado.

\section{Perfil do Pibid FAJESU}

A FAJESU é uma instituição de pequeno porte, e por isso mesmo não apresentou grandes variações. De todo modo, esta instituição registrava, segundo os dados do censo, 514 alunos, distribuídos pelos quatro cursos de licenciatura da instituição, sendo que desses quatro cursos, três fazem parte do Pibid: vale ressaltar que todos os cursos dessa instituição são todos noturnos (tabela 5). 


\begin{tabular}{l|c|c|c}
\cline { 2 - 3 } \multicolumn{1}{c|}{ Nome do Curso } & Turno e \% por turno & \multicolumn{2}{c}{} \\
\hline Letras - Inglês & Noturno & \% & Total \\
\hline Letras - Língua Portuguesa & 4 & $100 \%$ & 4 \\
\hline Matemática & 176 & $100 \%$ & 176 \\
\hline Pedagogia & 128 & $100 \%$ & 128 \\
\hline Total & 206 & $100 \%$ & 206 \\
\hline
\end{tabular}

Tabela 5: Quantidade de matrículas nos cursos de licenciatura da FAJESU por turno. Fonte: Microdados do censo da Educação Superior 2012/CAPES.

No que tange ao aproveitamento da cota de bolsas, esta instituição apresenta um aproveitamento de $87 \%$ (tabela 2), número também superior ao da UnB.

\begin{tabular}{l|c|c|c|c|c|c|c}
\cline { 2 - 8 } & \multicolumn{2}{c|}{ Situação do aluno } & \multicolumn{3}{c}{} \\
\hline $\begin{array}{c}\text { Nome do } \\
\text { Curso }\end{array}$ & Matrícula & Cursando & $\%$ & $\begin{array}{c}\text { Cota } \\
\text { Solicitada }\end{array}$ & $\begin{array}{c}\text { Qtde de } \\
\text { Bolsistas }\end{array}$ & $\begin{array}{c}\text { \% de } \\
\text { Aproveitamento } \\
\text { da Cota }\end{array}$ & $\begin{array}{c}\text { \% Por } \\
\text { Cur- } \\
\text { so }\end{array}$ \\
\hline Letras - Inglês & 4 & 2 & $50 \%$ & - & - & - & - \\
\hline $\begin{array}{l}\text { Letras - Língua } \\
\text { Portuguesa }\end{array}$ & 176 & 108 & $61 \%$ & 20 & 16 & $80 \%$ & $15 \%$ \\
\hline Matemática & 128 & 99 & $77 \%$ & 20 & 16 & $80 \%$ & $16 \%$ \\
\hline Pedagogia & 206 & 167 & $81 \%$ & 20 & 20 & $100 \%$ & $12 \%$ \\
\hline Total & 514 & 376 & $73 \%$ & 60 & 52 & $87 \%$ & $14 \%$ \\
\hline
\end{tabular}

Tabela 6: Quantidade de matriculados, quantidade de alunos na situação de "cursando", percentual de "cursando" em relação ao total de matriculados, cota de bolsas solicitadas, quantidade de bolsistas de cada curso, percentual de aproveitamento da cota em cada curso e percentual de bolsistas de cada curso em relação total em relação ao total de "cursando" FAJESU. Fonte: Microdados do censo da Educação Superior 2012/ CAPES

\section{Perfil do Pibid IFB}

No que diz respeito aos dados do IFB, a comparação com o número de matriculados ficou comprometida pelo fato de um dos dois participantes do programa na instituição - letras/espanhol - ser um curso novo, criado em 2012, motivo pelo qual não consta no censo de 2012. De todo modo, no que diz respeito ao outro curso participante (Dança) que pudemos comparar, 10\% dos estudantes matriculados neste curso fazem parte do programa tendo como referência o quantitativo de matrículas de 2012 (tabela 8), sendo ainda que se trata de um curso com turmas no período matutino e vespertino (Tabela 7). 


\begin{tabular}{|c|c|c|c|c|c|c|c|}
\hline \multirow[b]{2}{*}{ Nome do Curso } & \multicolumn{6}{|c|}{ Turno e $\%$ por turno } & \multirow[b]{2}{*}{ Total } \\
\hline & Matutino & $\%$ & Noturno & $\%$ & Vespertino & $\%$ & \\
\hline Dança & 103 & & 0 & $0 \%$ & 92 & $47 \%$ & 195 \\
\hline Química & 74 & & 67 & $48 \%$ & 0 & $0 \%$ & 141 \\
\hline Total & 177 & & 67 & $20 \%$ & 92 & $27 \%$ & 336 \\
\hline
\end{tabular}

Tabela 7: Quantidade de matrículas nos cursos de licenciatura do IFB por turno. Fonte: Microdados do censo da Educação Superior 2012.

\begin{tabular}{l|c|c|c|c|c|c|c}
\cline { 2 - 5 } & \multicolumn{2}{|c|}{ Situação do aluno } & \multicolumn{2}{c}{} \\
\hline $\begin{array}{c}\text { Nome do } \\
\text { Curso }\end{array}$ & Matrículas & Cursando & $\%$ & $\begin{array}{c}\text { Cota } \\
\text { Solicitada }\end{array}$ & $\begin{array}{c}\text { Qtde de } \\
\text { Bolsistas }\end{array}$ & $\begin{array}{c}\text { \% de } \\
\text { Aproveitamento } \\
\text { da Cota }\end{array}$ & $\begin{array}{c}\% \text { Por } \\
\text { Curso }\end{array}$ \\
\hline Dança & 195 & 195 & $100 \%$ & 20 & 19 & $95 \%$ & $10 \%$ \\
\hline Química & 141 & 141 & $100 \%$ & - & - & - & - \\
\hline Total & 336 & 336 & $100 \%$ & 20 & 19 & $95 \%$ & $6 \%$ \\
\hline
\end{tabular}

Tabela 8: Quantidade de matriculados, quantidade de alunos na situação de "cursando", percentual de "cursando" em relação ao total de matriculados, cota de bolsas solicitadas, quantidade de bolsistas de cada curso, percentual de aproveitamento da cota em cada curso e percentual de bolsistas de cada curso em relação total em relação ao total de "cursando" IFB. Fonte: Microdados do censo da Educação Superior 2012/CAPES.

\section{Algumas comparações}

As diferenças entre as IES vão além do perfil heterogêneo de oferta de cursos. Nesse sentido, embora já tenha sido apontado preliminarmente algumas diferenças entre essas IES, faz se necessário priorizar algumas comparações. Deste modo, a primeira comparação inevitável é o percentual de aproveitamento da cota de bolsas por IES e o percentual médio de aproveitamento da cota por curso (figura 1).

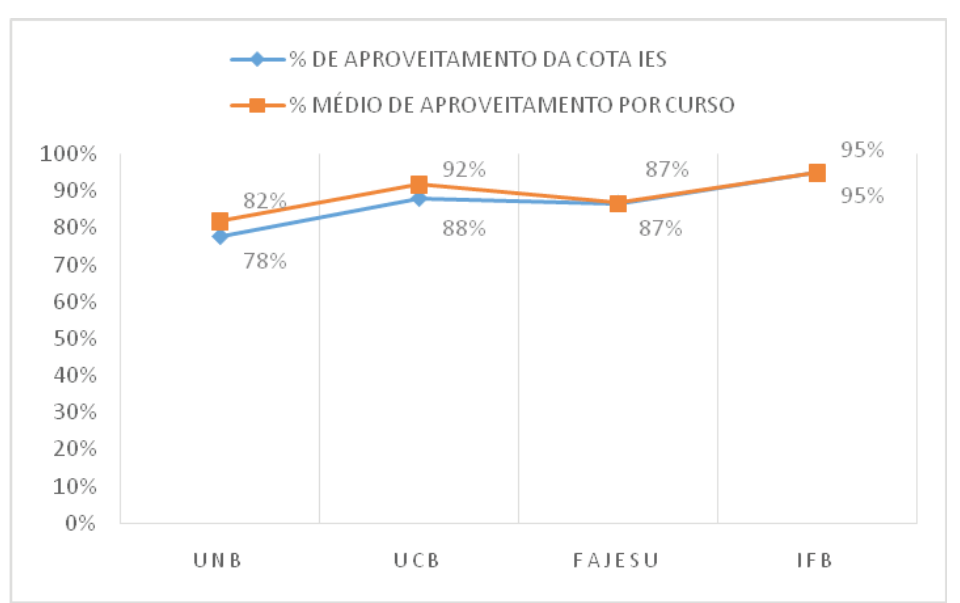

Figura 1: percentual de aproveitamento da cota de bolsas pela IES e percentual médio de aproveitamento da cota por curso pelos cursos participantes do Pibid. Fonte: CAPES. 
O que se pode inferir, a partir da figura 1 , é que, no caso do DF, as instituições privadas estão na frente tanto no aproveitamento da cota de bolsas quanto no aproveitamento por curso quando se considera instituições que possuem mais de um curso participante do programa (UnB, UCB e FAJESU). Esta diferença fica ainda mais visível entre as duas maiores IES participantes do programa: UnB e UCB. Isso implica considerar que em uma perspectiva quantitativa, as IES privadas do DF têm respondido mais satisfatoriamente ao programa quando o assunto é aproveitamento da cota de bolsas.

De todo modo, quando se considera a média de bolsistas por curso, os números se invertem, como demonstra a figura 2 :

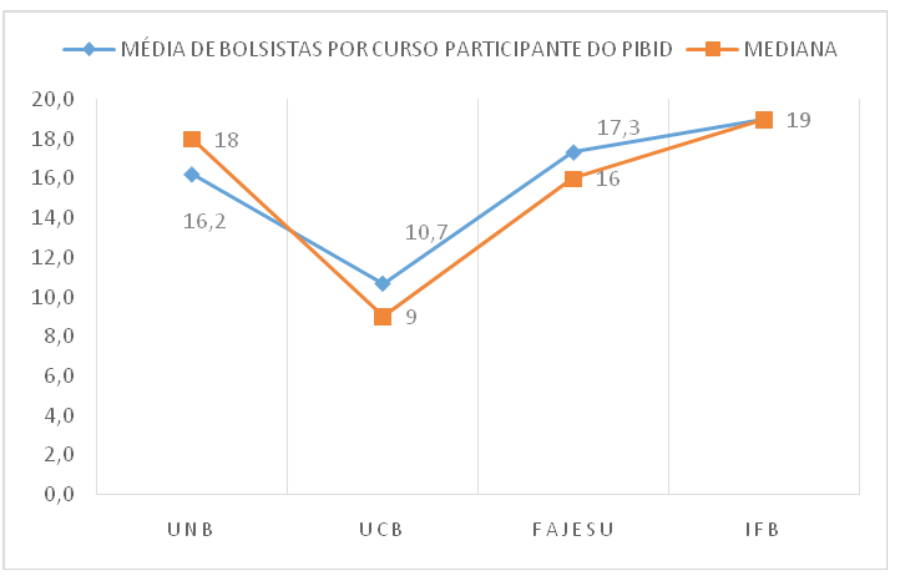

Figura 2: Média e mediana de bolsistas por curso participante do Pibid. Fonte: CAPES

Novamente considerando as IES com mais de um curso participante do programa (UnB, UCB e FAJESU), a UnB assume a liderança quando a comparação diz respeito à média de bolsistas por cursos. Antes de ser um ponto a favor dessa IES, esse dado expressa, mais uma vez, sua heterogênea participação no programa, expressada pela participação de poucos cursos e uma maior concentração de bolsistas por curso. Isso pode indicar que, no caso da $\mathrm{UnB}$, não há um gerenciamento institucional que tenha dado conta de uma inserção mais abrangente no programa, indicando que esta inserção ao que parece, se dá mais de forma individual (por curso) do que coletiva, a nível de instituição.

\section{Considerações e sugestões para estudos futuros}

A apresentação desses resultados certamente implica a inferência de algumas considerações e ressalvas. Nesse sentido, primeiramente, consideramos que tais resultados indicam, preliminarmente, acentuadas diferenças no gerenciamento do programa ora discutido - Pibid - quando se compara instituições públicas e privadas. Levando em consideração a participação minoritária das outras duas IES (IFB e FAJESU), a discussão inevitavelmente fica polarizada entre a UnB e a UCB. 
De todo modo, ressalvamos que esse tipo de inferência carece de um estudo mais aprofundado sobre a perspectiva e o papel institucional do programa em cada instituição. Concomitantemente, consideramos também que o fato de haver uma aderência de $100 \%$ dos cursos de licenciatura da UCB participando do programa, contra $52 \%$ da UnB, pode indicar mais do que uma aparente maior eficiência no gerenciamento do programa, e nesse sentido temos de ressalvar algumas questões que fugiram aos objetivos do presente estudo.

Quando falamos em IES privada, certamente temos que contextualizar que no caso de instituições desta natureza, o programa, que oferece bolsas, pode significar maior atratividade para os cursos, já que são cursos pagos, e já que as IES privadas amargam um histórico problema de evasão e preenchimento das vagas de seus cursos.

Contudo, em que pese o surgimento de tais hipóteses, a apresentação desses dados suscita uma discussão extremamente necessária no nosso ponto de vista: quem realmente gradua professores no Brasil, as IES públicas ou as IES privadas? Se levarmos em consideração que nos pressupostos do Ministério da Educação e da Capes a boa formação prática do professor deve perpassar experiências supostamente inovadoras no campo da docência - por isso a criação do programa - há de se considerar, no caso do DF, que a UCB tem atendido mais significativamente a tais pressupostos, estando seus alunos de licenciatura, nesta perspectiva, um passo adiante no processo formativo.

Ademais, pegando o DF e a UnB enquanto IES pública como referência, a conclusão mais precisa que podemos inferir é que sendo o Pibid o carro chefe da inovação e valorização da formação docente do MEC, trata-se de uma política ainda a ser ampliada, seja no número de bolsas, seja na aderência e gerenciamento do programa pela instituição. Os 5\% de participação - quando se leva em consideração a população de licenciandos - é um número tímido, uma vez que o intento do programa é valorizar e contextualizar a formação docente, além de incrementar, futuramente, a qualidade da educação básica.

Há ainda de se considerar o papel das IES privadas na formação de professores. A expressiva participação da UCB em termos de aproveitamento da cota e bolsas e aderência de cursos, exige, inevitavelmente, que se considere, em discussões futuras, o papel de instituições dessa natureza - privadas - na formação de professores.

Conclusivamente, ressaltamos que dada a natureza ampla e heterogênea do programa em tela - Pibid - e a quase inexistência de estudos sobre o mesmo comprometem o poder inferencial de qualquer pesquisa que venha ser feita, inclusive, desta. De todo modo, acreditamos que os resultados aqui apresentados e discutidos têm sua parcela de contribuição a partir do momento em que apresentam mais do que números, mas também hipóteses a serem consideradas em estudos futuros. 
Daniel de Freitas Nunes - Lucas Lopes de Santana - Kátia Augusta

Curado Pinheiro Cordeiro da Silva

\section{Referências}

BRASIL., DECRETO No 6.755, DE 29 DE JANEIRO DE 2009: institui a política nacional de formação de profissionais do magistério da Educação Básica, disciplina a atuação da Coordenação de Aperfeiçoamento de Pessoal de Nível Superior - CAPES no fomento a programas de formação inicial e continuada, e dá outras providências. Presidência da República: Brasília, 2009.

BRASIL. Lei 9394/96 - Lei de Diretrizes e Bases da Educação Nacional. Disponível em: <http://portal.mec.gov.br/arquivos/pdf/ldb.pdf.> Acesso em: 05 mar. 2014.

BRASIL. Ministério Da Educação - MEC; Fundação Coordenação de Aperfeiçoamento De Pessoal De Nível Superior - Capes; Fundo Nacional de Desenvolvimento da Educação - FNDE. AVISO DE CHAMAMENTO PÚBLICO MEC/CAPES/FNDE No 1/2007. Brasília: MEC, 2007.

CRESWELL, J. W. Educational research: planning, conducting, and evaluating quantitative and qualitative research. 4. ed. Boston, MA: Pearson, 2012.

FREITAS, H. C. L. Formação de professores no Brasil: 10 anos de embate entre projetos de formação. Educação e Sociedade. Campinas: v. 23, n. 80, p. 136-167, 2002.

FUNDAÇÃO COORDENAÇÃO DE APERFEIÇOAMENTO DE PESSOAL DE NÍVEL SUPERIOR - CAPES; Diretoria de Educação Básica Presencial - DEB. Relatório de Gestão 2011. Brasília: CAPES, 2012.

Programa Institucional de Bolsa de Iniciação. À Docência Edital. n. 061/2013. Brasília: CAPES, 2013.

RELATÓRIO DE PAGAMENTO DE BOLSAS PIBID. Disponível em: <http:// www.capes.gov.br/images/stories/download/bolsas/Relatorio-Bolsas-Pibid-03-2014.pdf>. Acesso em: 2 maio 2014

GATTI, B. A.; NUNES, M. M. R. (Org.). Formação de professores para o ensino fundamental: um estudo dos currículos das licenciaturas em pedagogia, Língua Portuguesa, Matemática e Ciências Biológicas. São Paulo: FCC/DPE, 2009.

INSTITUTO NACIONAL DE PESQUISAS EDUCACIONAIS ANÍSIO TEIXEIRA INEP. Estudo Exploratório do professor Brasileiro. Brasília: INEP, 2009.

Microdados para download. Disponível em: <http://portal.inep.gov.br/basica-levantamentos-acessar> Acesso em: 19 jun. 2014.

NÓVOA, A. Professores: imagens do futuro presente. Lisboa: Educa, 2009.

SLEICHER, A. F. In: MCKINKEY \& COMPANY. How the world best-performing school systems come out on top. Mckinkey\&Company, s/1, 2007. (Relatório)

\section{Notas}

${ }^{1}$ Os microdados de 2012 foram usados em virtude da coleta de 2013 ainda não ter sido divulgada.

${ }^{2}$ Usa-se aqui o mesmo conceito de matricula recomendado pelo INEP, ou seja: é considerado matriculado alunos na situação de vínculo de matrícula no curso, isso quer dizer que é considerado matriculado no curso alunos na situação de "cursando" ou "formado".

${ }^{3}$ Como a planilha de projetos aprovados da CAPES usa como critério de referência ao curso o nome, e não o código INEP do curso, usa-se aqui como parâmetro de quantificação dos cursos da IES o nome e não o código. Nesse sentido, quantitativo de cursos da instituição se conferidos a partir do código e não do nome podem variar pela seguinte questão: um curso de mesmo nome pode ter dois ou mais códigos que podem 
expressar informações e qualificações distintas sobre o curso; à distância, integral, matutino, vespertino e nortuno. Nesse sentido, um curso de mesmo nome, pode, a partir do código, ser quantificado como mais de um curso.

* Mestrando em Educação pela Universidade de Brasília (UnB), Brasília Distrito Federal - Brasil.

** Mestrando em Educação pela Universidade de Brasília (UnB), Brasília Distrito Federal - Brasil.

**** Professora Doutora da Universidade de Brasília (UnB), Brasília Distrito Federal - Brasil.

\section{Correspondência}

Daniel de Freitas Nunes - Universidade de Brasília, Campus Universitário Darcy Ribeiro, CEP: 70910900, Brasília, Distrito Federal, Brasil.

E-mail:danielfreitas@uft.edu.br - lucaslsantana@yahoo.com.br - katiacurado@unb.br

Recebido em 12 de junho de 2014

Aprovado em 24 de julho de 2014 